\title{
Comparative analysis of essential oil composition of Iranian and Indian Nigella sativa L. extracted using supercritical fluid extraction and solvent extraction
}

\author{
This article was published in the following Dove Press journal: \\ Drug Design, Development and Therapy \\ 28 July 2017 \\ Number of times this article has been viewed
}

\author{
Kourosh Hasanzadeh \\ Ghahramanloo' \\ Behnam Kamalidehghan ${ }^{2}$ \\ Hamid Akbari Javar ${ }^{3}$ \\ Riyanto Teguh Widodo' \\ Keivan Majidzadeh ${ }^{4}$ \\ Mohamed Ibrahim Noordin' \\ 'Department of Pharmacy, Faculty \\ of Medicine, University of Malaya, \\ Kuala Lumpur, Malaysia; ${ }^{2}$ Medical \\ Genetics Department, National \\ Institute of Genetic Engineering and \\ Biotechnology (NIGEB), ${ }^{3}$ Department \\ of Pharmaceutics, Faculty of Pharmacy, \\ Tehran University of Medical Sciences \\ (TUMS), ${ }^{4}$ Breast Cancer Research \\ Center (BCRC) Academic Center \\ for Education, Culture and Research, \\ Tehran, Iran
}

\begin{abstract}
The objective of this study was to compare the oil extraction yield and essential oil composition of Indian and Iranian Nigella sativa L. extracted by using Supercritical Fluid Extraction (SFE) and solvent extraction methods. In this study, a gas chromatography equipped with a mass spectrophotometer detector was employed for qualitative analysis of the essential oil composition of Indian and Iranian N. sativa L. The results indicated that the main fatty acid composition identified in the essential oils extracted by using SFE and solvent extraction were linoleic acid $(22.4 \%-61.85 \%)$ and oleic acid $(1.64 \%-18.97 \%)$. Thymoquinone $(0.72 \%-21.03 \%)$ was found to be the major volatile compound in the extracted $N$. sativa oil. It was observed that the oil extraction efficiency obtained from SFE was significantly $(P<0.05)$ higher than that achieved by the solvent extraction technique. The present study showed that SFE can be used as a more efficient technique for extraction of N. Sativa L. essential oil, which is composed of higher linoleic acid and thymoquinone contents compared to the essential oil obtained by the solvent extraction technique.
\end{abstract}

Keywords: Nigella sativa L., essential oil extraction, supercritical fluid extraction, solvent extraction, fatty acid composition, thymoquinone, linoleic acid

\section{Introduction}

Nigella sativa, an annual flowering plant of Ranunculaceae family, has been used in traditional medicine throughout Middle Eastern countries, such as Asia, Africa, and India, for various ailments. It is commonly used to treat asthma, ${ }^{1,2}$ but a recent study of $N$. sativa demonstrated the multiple mechanisms of actions for a range of therapeutic uses. These include its use in the remedy to treat hypercholesterolemia in menopausal women, with more benefits and less side effects than from other single pharmacological agents. ${ }^{3}$

The results of another study showed that methanolic extract of $N$. sativa seed inhibits SiHa human cervical cancer cell proliferation through apoptotic induction. It was found that the results of one study suggest an association between p38 $\beta$ not p $38 \alpha$ and oral cancer development. Additionally, the anti cancer activity of thymoquinone (TQ) indicated that the antitumor activity of TQ may be attributed to the downregulation of $\mathrm{p} 38 \beta$ MAPK. 5

$N$. sativa can efficiently reduce the number of cells with NF200 at all the CA1, CA2, and CA3 regions of hippocampus and parietal and frontal areas of the rat's brain; $N$. sativa can be used as a potential preventive supplement compound for the treatment of Alzheimer's disease. ${ }^{6}$ It is also used as an antitumor agent, ${ }^{7,8}$ diuretic agent, ${ }^{9}$ analgesic agent, ${ }^{10}$ anti-cestode and anti-nematode agent, ${ }^{11}$ antidiabetic agent,,${ }^{12,13}$ bactericide,${ }^{14}$ and
Correspondence: Mohamed Ibrahim Noordin

Department of Pharmacy, Faculty of Medicine, University of Malaya, 50603 Kuala Lumpur, Malaysia

Tel +60379677897

Fax +60 379674964

Email ibrahimn@um.edu.my 
antiulcerogenic agent. ${ }^{15}$ The antioxidant effect of $N$. sativa oil and its components may represent another mechanism that contributes to its antimalarial activity. ${ }^{16}$

The desirable effect of $N$. sativa on human diseases may be due to the presence of active compounds (ie, polyunsaturated fatty acids, TQ, phenolic compounds, and other natural antioxidants) in $N$. sativa oil composition. $N$. sativa seed contains $26.6 \%$ oil, of which the major fatty acids are linoleic acid (LA, $64.6 \%)$ and palmitic acid (20.4\%) as reported in a previous study. ${ }^{17}$ Cheikh-Rouhou et al ${ }^{18}$ also found that LA was the major unsaturated fatty acid in N. sativa $(50.3 \%$ "Tunisian NS" and $49.2 \%$ "Iranian $N S$ "). It was found that $N$. sativa seeds contain 36\%-38\% fixed oils, proteins, alkaloids, saponin, and $0.4 \%-2.5 \%$ essential oil, and it was reported that the $N$. sativa essential oil is mainly composed of TQ $(27.8 \%-57.0 \%)$, $\rho$-cymene (7.1\%-15.5\%), carvacrol (5.8\%-11.6\%), t-anethole $(0.25 \%-2.3 \%)$, 4-terpineol $(2 \%-6.6 \%)$, and longifolene $(1.0 \%-8.0 \%) .{ }^{19}$ Fatty acid profiles were identified for $N$. sativa seed oils. Also LA and oleic acids are the main fatty acids of $N$. sativa essential oil. In addition, the $N$. sativa essential oil contains considerable amounts of myristic acid (C14:0), arachidic acid (C20:0), and behenic acid (C22:0). ${ }^{20}$

Most properties of whole seeds or their extracts are mainly attributed to quinine constituents, TQ is the most abundant compound..$^{21} \mathrm{TQ}$, as the main constituent of the volatile oil from $N$. sativa seeds, has been reported to possess strong antioxidant properties. ${ }^{22}$ Based on a previous study, TQ, carvacrol, $\mathrm{t}$-anethole, and 4-terpineol were identified as active antioxidants and radical scavenging compounds in $N$. sativa. ${ }^{23}$ TQ can be used for the treatment of fungal skin infections. ${ }^{24}$ Previous researchers reported different contents of TQ that ranged from $27.8 \%$ to $57 \%$ in several Australian N. sativa oils. ${ }^{23}$

$N$. sativa oil is traditionally obtained by mechanical pressing or treating powdered N. sativa seed with organic solvents, most commonly hexane. Conventional solvent extraction techniques produce low-quality oil that requires extensive purification operations resulting in thermal degradation and loss of valuable compounds. ${ }^{25}$ The use of organic solvents and the necessity of recovering the solvent have led to a move toward cleaner extraction methods, such as supercritical fluid extraction (SFE). SFE is becoming an efficient and worldwide used technique to obtain valuable natural substances from complex materials. SFE- $\mathrm{CO}_{2}$ has been utilized as a nontoxic alternative to hexane and other organic solvents for the extraction of oil from corn germ, ${ }^{26}$ cottonseed, ${ }^{27}$ rapeseed, ${ }^{28}$ and other oil-bearing materials. ${ }^{29}$ Thus, the main objective of this study was to compare the oil extraction efficiency and essential oil composition of Iranian and Indian N. sativa L. oil extracted by SFE and solvent extraction techniques.

\section{Materials and methods}

Chemicals and materials, such as $N$. sativa seed (black cumin seed), were purchased from local markets in Iran and India. The pure standard of TQ (66\%) and LA (60\%) were provided by Aldrich Chemical Company (Milwaukee, WI, USA). High-performance liquid chromatography grade methanol and n-hexane were supplied by Fisher Scientific (Pittsburgh, PA, USA).

\section{Collection and storage of $N$. sativa seeds}

$N$. sativa L. seeds were cleaned under running tap water, rinsed with distilled water, and air-dried in oven at $40^{\circ} \mathrm{C}$ overnight. The dried seeds then were ground into powder and sieved through a $250 \mu \mathrm{m}$ filter. The samples were kept frozen in amber flasks until analyzed.

\section{Supercritical fluid extraction}

In this study, $150 \mathrm{~g}$ of the powdered sample was subjected into SFE equipment (SFE-1000F, Thar US Technology, Pittsburgh, PA, USA) at extraction temperature of $40^{\circ} \mathrm{C}$ under $60 \mathrm{MPa}$. SFE flow rate was maintained at $20 \mathrm{~mL} / \mathrm{min}$ using a variable flow restrictor. The yield was collected within 3 hours. The collected pressure and temperature were $0.1 \mathrm{MPa}$ and $25^{\circ} \mathrm{C}$, respectively. The extraction was carried out with pure $\mathrm{CO}_{2}$.

\section{Solvent methods}

$N$. sativa powder of $10 \mathrm{~g}$ was measured by mean of digital scale (Shimadzu, Tokyo, Japan) and placed in flask. A total of $50 \mathrm{~mL}$ of solvent was added to each flask. The top of the flasks was covered by aluminum foil. The flasks were shacked using Shaking Incubator (Heidolph Unimax 1010, Heidolph Instruments $\mathrm{GmbH} \& \mathrm{Co}$. KG Walpersdorfer, Schwabach, Germany) at 5-7 rpm for 4 hours. The extracts were filtered by One Man paper (no 1) twice. The extracts were evaporated by means of rotatory evaporator (Heidolph Laborota 4000 , Germany). The yields were measured by digital scale (Shimazu) and protected from light by aluminum foil. The oils were kept in a refrigerator $\left(-80^{\circ} \mathrm{C}\right)$ for further analysis.

\section{Gas chromatography-mass spectrometry}

Identification of fatty acid composition of extracted $N$. sativa oil was performed by means of a gas chromatography (Thermo Finnigan TRACE GC-Polaris Q, San Jose, CA, USA) equipped with mass spectrometry detector (Thermo Finnigan $)$ and DB-Wax column $(60 \mathrm{~m} \times 0.25 \mathrm{~mm}$ id $\times 0.25 \mu \mathrm{m}$ film thickness; Supleco, MA, USA). Helium was used as a carrier gas (1 $\mathrm{mL} / \mathrm{min})$. Oven temperature was programmed at $70^{\circ} \mathrm{C}$ for 5 minutes, then raised up to $230^{\circ} \mathrm{C}$ at $2^{\circ} \mathrm{C} / \mathrm{min}$ 
Table I The essential oil composition of Iranian and Indian Nigella sativa L. seed oils identified using GC-MS

\begin{tabular}{|c|c|c|c|c|c|c|c|c|}
\hline \multirow[t]{2}{*}{ Compound } & \multicolumn{2}{|c|}{ SFE, \% } & \multicolumn{2}{|c|}{ Hex, \% } & \multicolumn{2}{|c|}{ Met, \% } & \multicolumn{2}{|c|}{ Hex/Met, \% } \\
\hline & Ir & In & Ir & In & Ir & In & Ir & In \\
\hline$\rho$-cymene $e^{a, b}$ & 8.19 & 0.54 & 10.43 & 1.08 & - & - & 3.64 & 2.05 \\
\hline$\alpha$-thujene ${ }^{b}$ & 0.86 & - & - & - & 0.12 & - & 0.93 & - \\
\hline Thymoquinone $\mathrm{e}^{\mathrm{a}, \mathrm{b}}$ & 8.26 & 0.72 & 17.54 & 1.16 & 21.03 & 16.0 & 13.52 & 8.65 \\
\hline Carvacrola $^{\mathrm{a}, \mathrm{b}}$ & 1.65 & - & 2.63 & - & 3.67 & 4.83 & 1.98 & 1.34 \\
\hline Myristic acid ${ }^{b, c}$ & 0.34 & 0.29 & - & 0.26 & - & - & - & - \\
\hline Ascorbic acid & 8.07 & 6.81 & - & 15.63 & 5.31 & 5.86 & 6.93 & 7.73 \\
\hline Oleic acid ${ }^{\mathrm{b}, \mathrm{c}}$ & 2.86 & 18.97 & 1.64 & 19.54 & 6.54 & 2.85 & 5.99 & 4.53 \\
\hline Linoleic acid ${ }^{b, c}$ & 49.43 & 61.85 & 31.91 & 58.78 & 22.14 & 31.9 & 32.37 & 58.04 \\
\hline 4-terpineol $\left.\right|^{b, c}$ & 0.17 & - & - & - & 0.35 & $0.4 \mathrm{I}$ & - & - \\
\hline Camphor $^{\mathrm{a}}$ & - & 0.08 & 1.42 & - & - & 0.44 & - & 3.59 \\
\hline$t$-butylhydroquinone & - & 0.38 & - & - & 7.73 & 11.5 & 3.1 & - \\
\hline Valencene & - & - & 0.51 & 0.37 & - & - & - & - \\
\hline Acetic acid & - & - & 0.71 & - & 1.47 & - & - & - \\
\hline Decanoic acid & - & - & 7.15 & - & - & - & - & - \\
\hline Ledol & - & - & 2.92 & - & - & - & 2.41 & - \\
\hline Palmitic acid ${ }^{b, c}$ & - & - & - & - & - & - & $\mathrm{I} .44$ & 1.34 \\
\hline
\end{tabular}

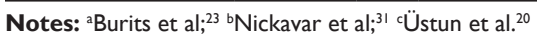

Abbreviations: GC-MS, gas chromatography-mass spectrometry; Hex, hexane; In, Indian; Ir, Iranian; Met, methanol; SFE, supercritical fluid extraction.

and held for 10 minutes at $230^{\circ} \mathrm{C}$. Injector temperature was $230^{\circ} \mathrm{C}$. EI mass spectra was recorded at $70 \mathrm{eV}$ ionization voltage over the mass range 40-400 u. For gas chromatographymass spectrometry (GC-MS) analysis, $0.5 \mu \mathrm{L}$ of extract and mixture solvent $(1: 10)$ containing $n$-hexane and methanol $(1: 1 \mathrm{v} / \mathrm{v})$ was injected under split mode $(1: 33)$.

\section{Results and discussion}

The chemical compositions of $N$. sativa seed identified by GC-MS are listed in Table 1. The gas chromatographs obtained from GC-MS analyses of oil extracted using solvent and SFE are shown in Figures 1-4. In total, 41 constituents were identified in the essential oils obtained from Iranian and Indian $N$. sativa seeds by using SFE and solvent extraction techniques.

In general, the oil extraction efficiency obtained from SFE was higher than the extracted yield achieved by solvent extraction technique. Among the main compounds identified by GC-MS, LA $(22.4 \%-61.85 \%)$ was the main fatty acid in the $N$. sativa oils extracted by both SFE and solvent extraction techniques. Besides LA, oleic acid (1.64\%-18.97\%),

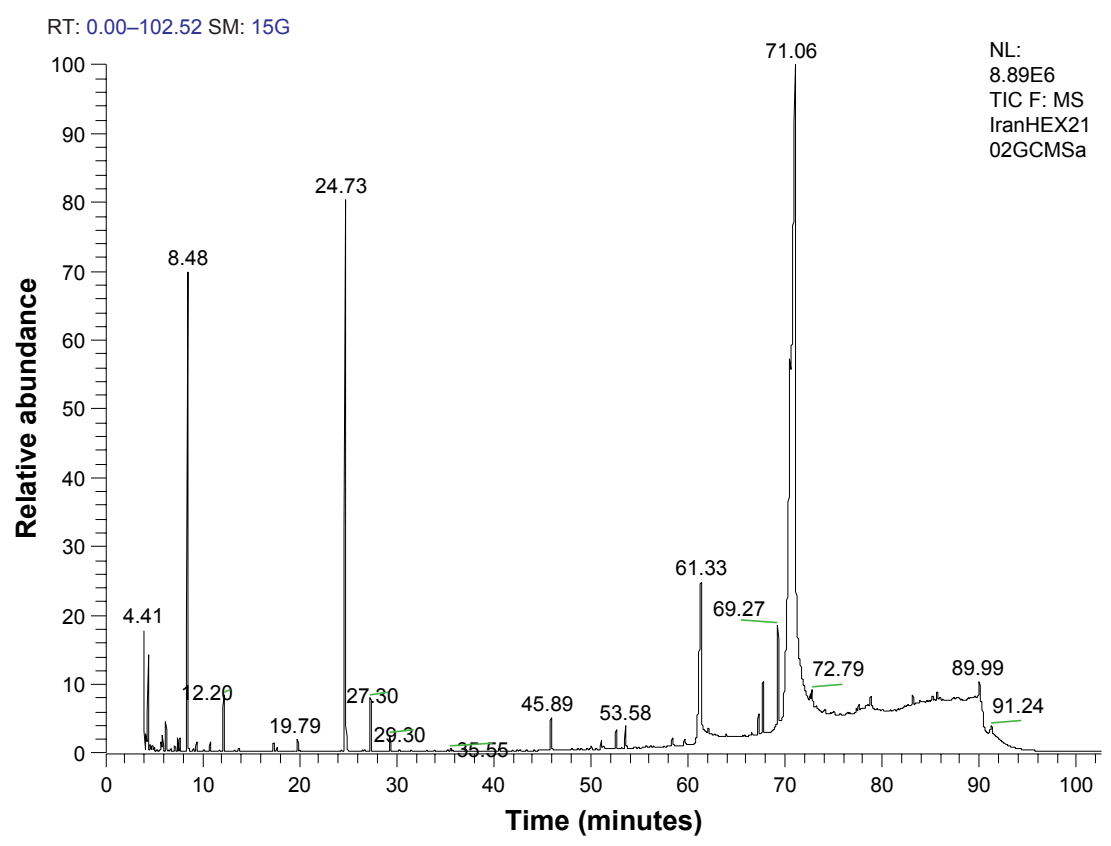

Figure I Gas chromatogram of Iranian Nigella sativa L. oil extracted by using hexane.

Abbreviations: GC-MS, gas chromatography-mass spectrometry; RT, room temperature; SM, solvent micro; NL, nonpolar lipids; TIC F, total ion current focusing; MS, mass spectrometry. 


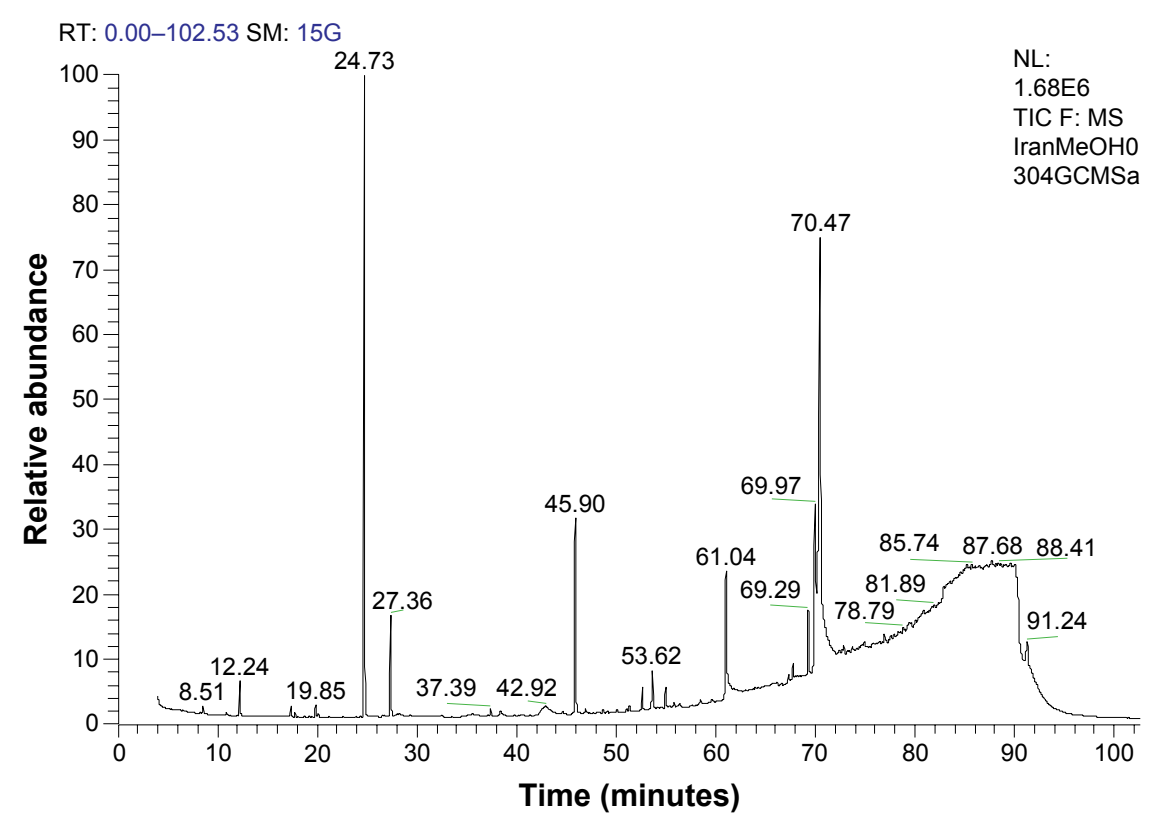

Figure 2 Gas chromatogram of Iranian Nigella sativa L. oil extracted by using methanol.

Abbreviations: GC-MS, gas chromatography-mass spectrometry; RT, room temperature; SM, solvent micro; NL, nonpolar lipids; TIC F, total ion current focusing; MS, mass spectrometry.

decanoic acid (7.15\%), eicosadienoic acid (2.56\%), palmitic acid (1.34\%-1.44\%), propanoic acid (0.79\%), acetic acid $(0.71 \%)$, heneicosanedioic acid $(0.65 \%)$, and myristic acid $(0.29 \%-0.34 \%)$ were found to be the major compounds identified in essential oils obtained from the Iranian and Indian $N$. sativa seed.

TQ was the main volatile oil component identified in this study $(0.72 \%-21.03 \%)$. Some noticeable compounds such as $t$-butylhydroquinone $(0.3 \%-11.5 \%)$, carvacrol
$(1.34 \%-4.83 \%), \alpha$-phellandrene $(1.66 \%)$, longifolene $(0.06 \%)$, pseudopelletierine $(0.15 \%)$, neolignan $(0.01 \%)$, eremophilene $(0.18 \%)$, methyl palmitoleate $(0.65 \%)$, limonene $(0.32 \%),{ }^{1,2}$ cuparene $(0.1 \%)$, arsacol $(0.43 \%), 2,3$-epoxycarane, (E)-4-isopropyl-5-methylhexa-2,4-dien-1-ol (1.05\%), 3 -cyclohexene-1-carboxaldehyde,1,3,4-trimethyl (0.4\%), tetraacetyl-d-xylonic nitrile $(0.1 \%)$, thujol $(0.12 \%)$, ocimene $(0.09 \%)$, cis-p-mentha-2,8-dien-1-ol $(0.32 \%)$, benzenemethanol, $\alpha, \alpha, 4$-trimethyl $(0.15 \%)$, ethyl iso-allocholate $(0.08 \%)$,

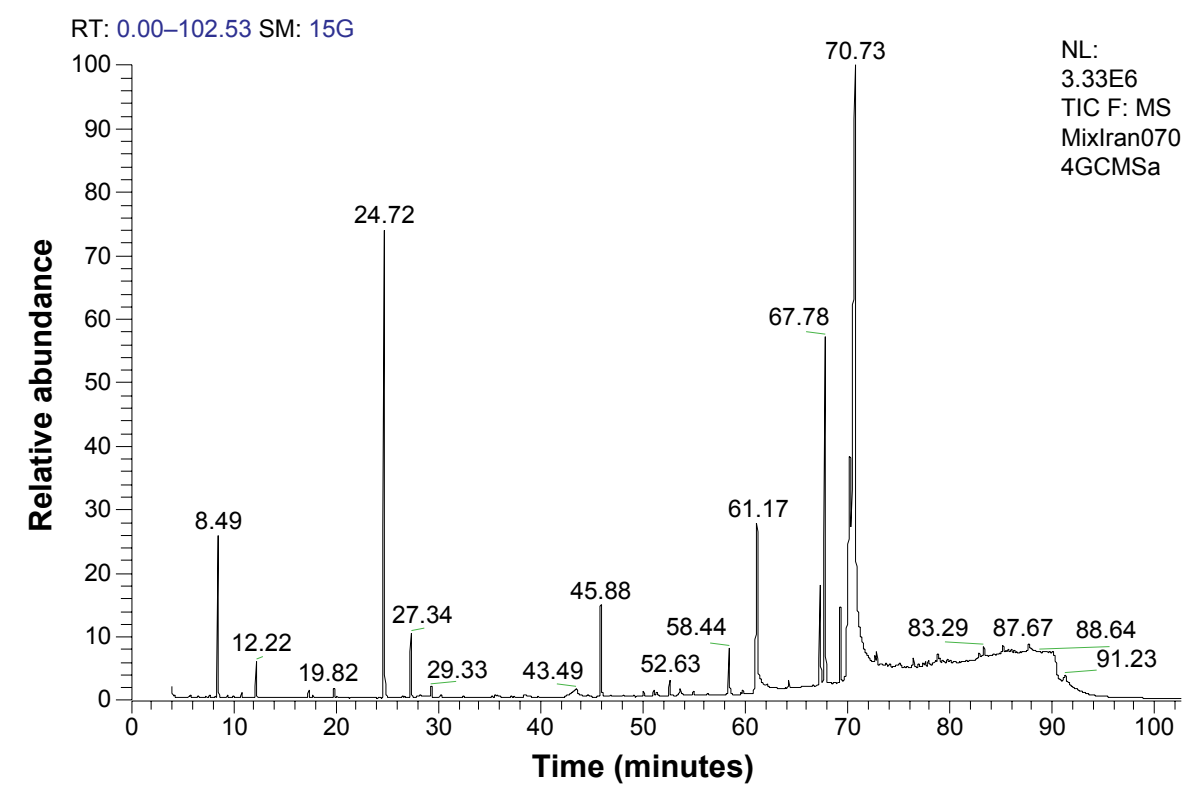

Figure 3 Gas chromatogram of Iranian Nigella sativa L. oil extracted by using methanol/hexane.

Abbreviations: GC-MS, gas chromatography-mass spectrometry; RT, room temperature; SM, solvent micro; NL, nonpolar lipids; TIC F, total ion current focusing; MS, mass spectrometry. 


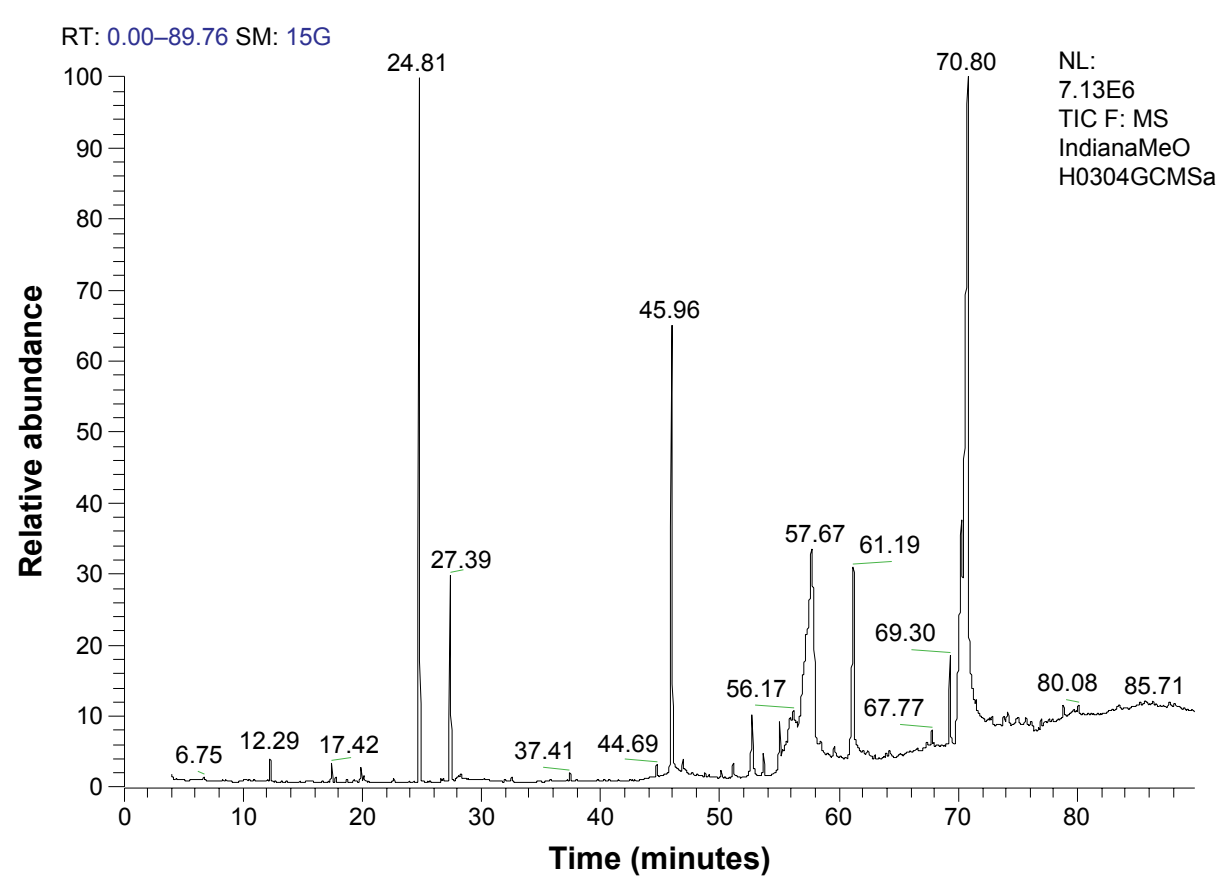

Figure 4 Gas chromatogram of Indian Nigella sativa L. oil extracted by using methanol.

Abbreviations: GC-MS, gas chromatography-mass spectrometry; RT, room temperature; SM, solvent micro; NL, nonpolar lipids; TIC F, total ion current focusing; MS, mass spectrometry.

benzeneacetonitrile, 4-hydroxy $(0.33 \%)$, 1-heptatriacontanol $(2.06 \%)$, and butylated hydroxytoluene ${ }^{1}(0.49 \%)$ were identified in essential oil obtained from Iranian and Indian $N$ sativa seeds.

The results indicate that the LA of Indian $N$. sativa oil extracted by SFE method was higher than the fatty acid contents measured for the other samples; while the essential oil extracted from Iranian sativa seeds using solvent extraction technique (methanol) contained the highest TQ content $(21.03 \%)$ compared to TQ recorded in the other samples. The present results are in agreement with the results of previous researchers ${ }^{21,23}$ who pointed out that the main compounds in the $N$. sativa essential oil were TQ, carvacrol, $\rho$-cymene, and 4-terpineol. Regarding the extraction efficiency obtained by using SFE, this study is in accordance with Kao et al, ${ }^{30}$ who indicated that the oil extraction using SFE resulted in higher content of compounds compared to solvent extraction technique.

\section{Conclusion}

The present study shows that SFE and solvent extraction methods have both advantages and disadvantages for the extraction of the essential oil and volatile oil components. Based on the results, SFE has been proven to be an efficient method of extraction. Solvent extraction can be utilized in extraction of some compounds, such as TQ. The present study also demonstrated that SFE is more efficient for extraction of essential oil from $N$. sativa L. seed compared to the solvent extraction technique. The essential oil obtained from SFE process contained more LA than that achieved by solvent extraction. It was observed that the oil extraction efficiency obtained from SFE is higher than that achieved by solvent extraction technique. According to this research, N. sativa oil has some bioactive compounds such as TQ and LA.

\section{Disclosure}

The authors report no conflicts of interest in this work.

\section{References}

1. El Tahir KE, Ashour M, Al-Harbi MM. The respiratory effects of the volatile oil of the black seed Nigella sativa in guinea-pigs: elucidation of the mechanism(s) of action. Gen Pharmacol. 1993;24(5):1115-1122.

2. Abbas AT, Abdel-Aziz MM, Zalata K, Abd A-GT-D. Effect of dexamethasone and Nigella sativa on peripheral blood eosinophil count, IgG1 and IgG2a, cytokine profiles and lung inflammation in murine model of allergic asthma. Egypt J Immunol. 2004;12(1):95-102.

3. Ibrahim RM, Hamdan NS, Mahmud R, et al. A randomised controlled trial on hypolipidemic effects of Nigella sativa seeds powder in menopausal women. J Transl Med. 2014;12(1):82.

4. Hasan TN, Shafi G, Syed NA, et al. Methanolic extract of Nigella sativa seed inhibits $\mathrm{SiHa}$ human cervical cancer cell proliferation through apoptosis. Nat Prod Commun. 2013;8(2):213-216.

5. Abdelfadil E, Cheng Y-H, Bau D-T, et al. Thymoquinone induces apoptosis in oral cancer cells through p $38 \beta$ inhibition. Am J Chin Med. 2013;41(03):683-696.

6. Abdullatiff L, Norsharina I, Musalmah M, Maznah I. Nigella sativa oil and thymoquinone protects amyloid â peptide (Aâ)-induced cell death in cultured cerebellar neurons. Iranian Pharmaceutical Sciences Conference (IPSC), Tehran, Iran; 2006. 
7. Salomi N, Nair S, Jayawardhanan K, Varghese C, Panikkar K. Antitumour principles from Nigella sativa seeds. Cancer Lett. 1992;63(1):41-46.

8. El Daly E. Protective effect of cysteine and vitamin E, Crocus sativus and Nigella sativa extracts on cisplatin-induced toxicity in rats. JPharm Belg. 1997;53(2):87-93; discussion 93-95.

9. Zaoui A, Cherrah Y, Lacaille-Dubois M, Settaf A, Amarouch H, Hassar M. [Diuretic and hypotensive effects of Nigella sativa in the spontaneously hypertensive rat]. Therapie. 1999;55(3):379-382.

10. Khanna T, Zaidi F, Dandiya P. CNS and analgesic studies on Nigella sativa. Fitoterapia. 1993;64:407-410.

11. Mahmoud M, El-Abhar H, Saleh S. The effect of Nigella sativa oil against the liver damage induced by Schistosoma mansoni infection in mice. J Ethnopharmacol. 2002;79(1):1-11.

12. Al-Hader A, Aqel M, Hasan Z. Hypoglycemic effects of the volatile oil of Nigella sativa seeds. Pharmaceut Biol. 1993;31(2):96-100.

13. El-Shabrawy O, Nada S. Biological evaluation of multicomponent tea used as hypoglycemic in rats. Fitoterapia. 1996;67(2):99-102.

14. El-Kamali H, Ahmed A, Mohammed A, Yahia A, El-Tayeb I, Ali A. Antibacterial properties of essential oils from Nigella sativa seeds, Cymbopogon citratus leaves and Pulicaria undulata aerial parts. Fitoterapia. 1998;69(1):77-78.

15. El-Dakhakhny M, Barakat M, Abd El-Halim M, Aly S. Effects of Nigella sativa oil on gastric secretion and ethanol induced ulcer in rats. J Ethnopharmacol. 2000;72(1):299-304.

16. Abdulelah H, Zainal-Abidin B. In vivo anti-malarial tests of Nigella sativa (black seed) different extracts. Am J Pharmacol Toxicol. 2007; 2(2):46.

17. Şener B, Küsmenoğlu S, Mutlugil A, Bingöl F. A study with the seed oil of Nigella sativa. Gazi Ecz Fak Der. 1985;2(1):1-8.

18. Cheikh-Rouhou S, Besbes S, Hentati B, Blecker C, Deroanne C, Attia H. Nigella sativa L.: Chemical composition and physicochemical characteristics of lipid fraction. Food Chemistry. 2007;101(2):673-681.

19. Hosseinzadeh H, Parvardeh S. Anticonvulsant effects of thymoquinone, the major constituent of Nigella sativa seeds, in mice. Phytomedicine. 2004;11(1):56-64.
20. Üstun G, Kent L, Cekin N, Civelekoglu H. Investigation of the technological properties of Nigella sativa (black cumin) seed oil. $J \mathrm{Am}$ Oil Chem Soc. 1990;67(12):958-960.

21. D'Antuono LF, Moretti A, Lovato AF. Seed yield, yield components, oil content and essential oil content and composition of Nigella sativa L. and Nigella damascena L. Ind Crops Prod. 2002;15(1):59-69.

22. Houghton PJ, Zarka R, de las Heras B, Hoult J. Fixed oil of EM EMTYPE. Planta med. 1995;61(01):33-36.

23. Burits M, Bucar F. Antioxidant activity of Nigella sativa essential oil. Phytother Res. 2000;14(5):323-328.

24. Aljabre SHM, Randhawa MA, Akhtar N, Alakloby OM, Alqurashi AM, Aldossary A. Antidermatophyte activity of ether extract of Nigella sativa and its active principle, thymoquinone. J Ethnopharmacol. 2005; 101(1):116-119.

25. Johnson, L. Theoretical, comparative and historical analyses of alternative technologies for oilseeds extraction. In: Wan PJ, Wakelyn PJ, editors. Technology and solvents for extracting oilseeds and nonpetroleum oils. Champaign, IL: AOCS Press. 2007:5-47.

26. Christianson D, Friedrich J, List G, et al. Supercritical fluid extraction of dry-milled corn germ with carbon dioxide. J Food Sci. 1984;49(1): 229-232.

27. Kuk M, Hron Sr R. Supercritical carbon dioxide extraction of cottonseed with co-solvents. J Am Oil Chem Soc. 1994;71(12):1353-1356.

28. Temelli F. Extraction of triglycerides and phospholipids from canola with supercritical carbon dioxide and ethanol. J Food Sci. 1992; 57(2):440-443.

29. Alexander W, Brusewitz G, Maness N. Pecan oil recovery and composition as affected by temperature, pressure, and supercritical $\mathrm{CO}_{2}$ flow rate. J Food Sci. 1997;62(4):762-766.

30. Kao T-H, Chien J-T, Chen B-H. Extraction yield of isoflavones from soy-bean cake as affected by solvent and supercritical carbon dioxide. Food Chem. 2008;107(4):1728-1736.

31. Nickavar B, Mojab F, Javidnia K, Roodgar Amoli MA. Chemical composition of the fixed and volatile oils of Nigella sativa $\mathrm{L}$. from Iran. Zeitschrift für Naturforschung C. 2003;58.9-10:629-631.
Drug Design, Development and Therapy

\section{Publish your work in this journal}

Drug Design, Development and Therapy is an international, peerreviewed open-access journal that spans the spectrum of drug design and development through to clinical applications. Clinical outcomes, patient safety, and programs for the development and effective, safe, and sustained use of medicines are the features of the journal, which

\section{Dovepress}

has also been accepted for indexing on PubMed Central. The manuscript management system is completely online and includes a very quick and fair peer-review system, which is all easy to use. Visit http://www.dovepress.com/testimonials.php to read real quotes from published authors. 